\title{
Color Change Evaluation of Denture Soft Lining Materials in Coffee and Tea
}

\author{
Serra OĞUZ11, Mustafa Murat MUTLUAY ${ }^{2}$, Orhan Murat DOGAN ${ }^{3}$ and Bülent BEK \\ ${ }^{1}$ Gazi University, Faculty of Dentistry, Department of Prosthodontics, Ankara, Turkey \\ ${ }^{2}$ University of Oslo, Faculty of Dentistry, Department of Prosthodontics, Oslo, Norway \\ ${ }^{3}$ Cumhuriyet University, Faculty of Dentistry, Department of Prosthodontics, Sivas, Turkey \\ Corresponding author, Serra OGUZ; E-mail: serraoguz@hotmail.com
}

Received August 28, 2006 /Accepted November 14, 2006

\begin{abstract}
This study evaluated the color stability of soft denture liners after being exposed to coffee and tea solutions for different time periods. Four soft denture liners and a denture base polymer were tested. Five specimens of each material were immersed in either coffee or tea solution at $50 \pm 1^{\circ} \mathrm{C}$ for one, three, nine, 24, 48, and 96 hours. Color measurements were made using a reflectance spectrophotometer before and after the specimens were exposed to the solutions. After 96 hours' immersion in coffee and tea solutions, coffee produced more marked color changes than did tea for all the materials tested. Surface roughness $(\mathrm{Ra})$ of the materials after being cured against a stainless steel surface was also measured with a contacttype surface roughness measuring instrument. Due to the different surface structures, which thus accounted for the different $\mathrm{Ra}$ values, the materials behaved differently when immersed in different solutions.
\end{abstract}

Keywords: Liner, Color, Roughness

\section{INTRODUCTION}

Some edentulous patients cannot tolerate a conventional hard denture base due to the presence of a thin and relatively non-resilient mucosa or due to severe alveolar resorption ${ }^{11}$. In such clinical situations, soft denture liners are used to assist in providing an even distribution of functional loads on the denture-bearing area by avoiding local stress concentrations. Besides, soft denture liners also offer the added advantage of engaging undercuts, and thereby improving retention ${ }^{2-4}$.

However, a number of problems associated with the use of soft denture liners have been reported, such as hardening with time (or loss of softness), color changes, colonization by microorganisms, poor tear strength, and debonding from the denture base ${ }^{2,5,6)}$.

Color stability is crucial for all dental restorative materials in terms of acceptable esthetic appearance. As such, it is considered as one of the criteria that determines the serviceability of these materials ${ }^{7,8)}$. Several factors may contribute to the discoloration of soft denture liners after long-term use. These factors include stain accumulation, water sorption, dissolution of ingredients, degradation of intrinsic pigments, and surface roughness ${ }^{7,9}$. It is well known that beverages such as tea, coffee, wine, and some artificial dyes used in food rapidly increase the discoloration of both denture base polymers and soft denture liners ${ }^{9,10}$. Tea leaves contain high amounts of flavonoid and methylxanthine compounds which give tea its flavor and functional properties. However, teaflavins in tea leaves cause a yellowish-brown discoloration. As for coffee, its chemistry changes with raising conditions, storage time, temperature, and humidity. Then similarly, caffeine and caffeic acid in coffee-and also in tea-may cause discoloration of the polymeric materials ${ }^{11}$.

Color changes in dental materials may be assessed visually or by colorimetry. Colorimetric measurements permit a reproducible means of color determination and eliminate the subjective interpretation of visual color comparisons. The CIELAB system recommended by the Commission Internationale de I'Eclairage (International Commision on Illumination) is an approximately uniform color space that determines color changes and makes it possible to evaluate the amount of perceptible color changes in each sample ${ }^{12-14)}$. The magnitude of total color difference is represented by a single number, $\Delta \mathrm{E}^{*} \mathrm{ab}$. According to this system, color differences with $\Delta \mathrm{E}^{*}$ ab values corresponding to 1.0 are regarded as perceptible; and in dentistry, $\Delta \mathrm{E}^{*} \mathrm{ab}$ values lower than 3.3 are acceptable ${ }^{12)}$.

The purpose of this study was to quantitatively analyze the color stability of soft denture liners-polymerized with different techniques-after exposure to coffee and tea in an accelerated aging test. The relationship between color change and surface roughness of the materials was also investigated. The hypothesis to be tested in this study was that stainability of soft denture liner materials was related to material type, polymerization conditions, type of staining solution, as well as surface roughness of material.

\section{MATERIALS AND METHODS}

\section{Materials used}

Two autopolymerizing silicon soft liners (additional polymerization type), one silicon heat-curing soft liner (condensation curing type), one autopolymerizing acrylic soft liner (light-activated), and 
Table 1 Materials used in the study

\begin{tabular}{|c|c|c|c|}
\hline Brand name (Code) & Components & Manufacturer & Processing method \\
\hline Meliodent (MEL) & $\begin{array}{l}\text { Methyl methacrylate, } \\
\text { ethyl hexyl acrylate, } \\
\text { glycol dimethacrylate, } \\
\text { N-octyl methacrylate, } \\
\text { dimethyl p-toluidine }\end{array}$ & $\begin{array}{l}\text { Heraeus Kulzer, Hanau, } \\
\text { Germany }\end{array}$ & $\begin{array}{c}\text { Compression mold } \\
\text { technique, heat-polymerized }\end{array}$ \\
\hline Astron Light (AL) & $\begin{array}{l}\text { Butyl methacrylate, } \\
\text { Bis-EMA, PEMA }\end{array}$ & $\begin{array}{c}\text { Astron Dental, Lake Zurich, } \\
\text { IL, USA }\end{array}$ & Light activation \\
\hline Molloplast-B (MLP) & $\begin{array}{l}\text { Condensation silicone } \\
\text { material, PMMA, } \gamma- \\
\text { methacryloyloxy- } \\
\text { propyltrimethoxysilane }\end{array}$ & $\begin{array}{c}\text { Detax GmbH, Ettlingen, } \\
\text { Germany }\end{array}$ & Heat-polymerized \\
\hline GC Reline Soft (GC) & $\begin{array}{l}\text { Silicon dioxide, Vinyl } \\
\text { dimethyl polysiloxane, } \\
\text { Hydrogen polysiloxane }\end{array}$ & GC Co., Tokyo, Japan & Autopolymerizing \\
\hline Silagum Automic Comfort (SC) & $\begin{array}{l}\text { Vinylsilicon, hydrogen } \\
\text { silicon, aerosil, } \\
\text { additives, Pt compounds }\end{array}$ & DMG, Hamburg, Germany & Autopolymerizing \\
\hline
\end{tabular}

one heat-curing acrylic resin were used (Table 1).

Specimens were obtained using a stainless steel mold with a diameter of $50 \mathrm{~mm}$ and a thickness of 3 mm. GC Reline Soft (GC), Silagum Automix Comfort (SC), and Meliodent (MEL) materials were shaped in the molds, which were then placed under a pressure of $30 \mathrm{MPa}$ (Reco Hydromatic, Reco Dental, Wiesbaden, Germany) for approximately five minutes. The soft liners were polymerized at $40-50^{\circ} \mathrm{C}$ for 10 minutes, and denture base resin was polymerized at $100^{\circ} \mathrm{C}$ for 30 minutes in dental flasks using a conditioner (Kotterman Labortechnik, Hannover, Germany). For the heat-polymerized Molloplast-B material (MLP), the same stainless steel molds were used by placing a polyethylene film in it to prevent MLP from bonding to the mold. Samples were then polymerized according to the manufacturer's recommendations at $100^{\circ} \mathrm{C}$ for two hours. Light-activated Astron Light material (AL) was placed in the same molds covered by a transparent glass plate and cured by visible light for 10 minutes in a Triad 2000 curing unit (Dentsply York Division, PA, USA).

Five disk specimens of each material were prepared for immersion in coffee and tea solutions, respectively. As a result, a total of 50 specimens were obtained.

\section{Staining solutions}

A standard solution of tea was prepared from $10 \mathrm{~g}$ of a commercial brand (Earl Grey Tea, R. Twinings
\& Company Limited, London, England) in $1 \mathrm{~L}$ boiled distilled water for five minutes, and the liquid was decanted. Then, the solution was allowed to cool to $50^{\circ} \mathrm{C}$. To prepare a standard solution of coffee, $60 \mathrm{~g}$ of coffee (Coop Kaffe Mild \& Rund, Coop Norge Kaffe AS, Oslo, Norway) was put on a filter paper (Kaffefilter $1 \times 4$, Coop Norden AB, Goteborg, Sweeden) and $1 \mathrm{~L}$ boiled distilled water was passed through the coffee. This solution was filtered again and allowed to cool to $50^{\circ} \mathrm{C}$.

Five specimens of each material were placed in glass containers and filled with tea or coffee. The specimens were then placed in an incubator and stored for one, three, nine, 24, 48, and 96 hours at $50 \pm 1{ }^{\circ} \mathrm{C}$. After removing the specimens from the staining solutions, they were dipped in a cleansing solution consisting of $10 \mathrm{ml}$ soap (Mucoderma, Merz + Co, Frankfurt/Main, Germany) and $700 \mathrm{ml}$ distilled water, and moved up and down 10 times. After cleansing, the specimens were placed in distilled water and moved up and down 10 times to rinse the soap from the surface. Excess fluid on the surface was removed using a tissue paper. After color measurements at the given time intervals were carried out, the specimens were re-immersed in fresh staining solutions.

\section{Color measurement}

Color measurements were made using a reflectance spectrophotometer (Model CM-3500d, Minolta, Japan) 
Table 2 Means and standard deviations (SD) of total color difference ( $\left.\Delta \mathrm{E}^{*} \mathrm{ab}\right)$ caused by tea as a function of time

\begin{tabular}{|c|c|c|c|c|c|}
\hline & $\mathrm{AL}$ & GC & $\mathrm{SC}$ & MLP & MEL \\
\hline $1 \mathrm{hr}$ & $2.4(1.04)$ & $1.2(0.89)$ & $0.4 \quad(0.32)$ & $0.5 \quad(0.23)$ & $0.6 \quad(0.24)$ \\
\hline $3 \mathrm{hr}$ & $5.8(1.72)$ & $2.6 \quad(1.57)$ & $1.02(0.53)$ & $0.9 \quad(0.64)$ & $1.22(0.7)$ \\
\hline $9 \mathrm{hr}$ & $7.2(2.11)$ & $3.6 \quad(1.55)$ & $1.8 \quad(0.59)$ & $2.4 \quad(1.1)$ & $1.54(0.43)$ \\
\hline $24 \mathrm{hr}$ & $7.6(1.82)$ & 3.77 (1.19) & $4.4 \quad(1.34)$ & $2.9 \quad(1.93)$ & $2.54(0.42)$ \\
\hline $48 \mathrm{hr}$ & $11 \quad(1.54)$ & $4.47(2.81)$ & $4.3 \quad(1.09)$ & $3.4 \quad(1.76)$ & $2.6 \quad(1.07)$ \\
\hline $96 \mathrm{hr}$ & $11.95(1.96)^{\mathrm{a}}$ & $7.22(0.68)^{b}$ & $5.81(1.28)^{b}$ & $5.13(4.72)^{b}$ & $3.07(0.56)^{b}$ \\
\hline
\end{tabular}

Groups with the same superscript letters were not significantly different $(\mathrm{p}>0.05)$.

Table 3 Means and standard deviations (SD) of total color difference ( $\Delta \mathrm{E}^{*} \mathrm{ab}$ ) caused by coffee as a function of time

\begin{tabular}{clllllllllll}
\hline & \multicolumn{2}{c}{ AL } & \multicolumn{2}{c}{ GC } & \multicolumn{2}{c}{ SC } & \multicolumn{2}{c}{ MLP } & \multicolumn{2}{c}{ MEL } \\
\hline $1 \mathrm{hr}$ & 5 & $(2.8)$ & 1.3 & $(0.48)$ & 2.1 & $(1.23)$ & 0.8 & $(0.47)$ & 0.8 & $(0.47)$ \\
$3 \mathrm{hr}$ & 10.9 & $(3.29)$ & 3.2 & $(0.98)$ & 4.5 & $(1.42)$ & 1.8 & $(1.29)$ & 1.65 & $(0.62)$ \\
$9 \mathrm{hr}$ & 15 & $(2.09)$ & 5.6 & $(2.13)$ & 5.1 & $(2.13)$ & 2.7 & $(1.92)$ & 2.3 & $(0.72)$ \\
$24 \mathrm{hr}$ & 23.3 & $(1.45)$ & 10.7 & $(2.94)$ & 7.5 & $(1.04)$ & 3.3 & $(1.63)$ & $2.88(0.91)$ \\
$48 \mathrm{hr}$ & 28 & $(1.01)$ & 12.64 & $(1.68)$ & 8.9 & $(1.94)$ & 5 & $(2.96)$ & $4.28(1.12)$ \\
$96 \mathrm{hr}$ & 31.91 & $(1.16)^{\mathrm{a}}$ & 16.68 & $(0.71)^{\mathrm{b}}$ & 10.08 & $(1.18)^{\mathrm{c}}$ & 8.22 & $(0.36)^{\mathrm{c}, \mathrm{d}}$ & 7.3 & $(1.52)^{\mathrm{d}}$ \\
\hline
\end{tabular}

Groups with the same superscript letters were not significantly different $(\mathrm{p}>0.05)$.

before and after the specimens were exposed to the staining solutions. The spectrophotometer system was connected to a computer system (Spectra Magic, Minolta, Japan). Measuring characteristics of the spectrophotometer were standard illuminant D65 and illumination/viewing geometry $\mathrm{d} / 8$ degrees. The spectrophotometer system was calibrated before and after measurements using white and black standards. Three readings were made for each specimen, and the mean values were calculated and recorded with the CIELAB color scale of Commission Internationale de I'Eclairage, where $\mathrm{L}^{*}$ represented the light-dark character, $a^{*}$ represented the red-green character, and $b^{*}$ represented the yellow-blue character. As the CIELAB system was based on rectangular coordinates, the equation for calculating total color difference, $\Delta \mathrm{E}^{*} \mathrm{ab}$, was as follows:

$$
\Delta \mathrm{E}^{*} \mathrm{ab}=\left[\left(\Delta \mathrm{L}^{*}\right)^{2}+\left(\Delta \mathrm{a}^{*}\right)^{2}+\left(\Delta \mathrm{b}^{*}\right)^{2}\right]^{1 / 2}
$$

where $\Delta \mathrm{L}^{*}, \Delta \mathrm{a}^{*}$, and $\Delta \mathrm{b}^{*}$ are differences in the respective $L^{*}, a^{*}$, and $b^{*}$ values. A discoloration of $\Delta \mathrm{E}^{*} \mathrm{ab}>1.0$ was considered as acceptable up to the value of $\Delta \mathrm{E}^{*} \mathrm{ab}=3.3$, which was considered to be the upper limit of acceptability in subjective visual evaluations. Discoloration above this level was considered as unacceptable ${ }^{15}$.

\section{Roughness measurement}

Surface roughness (Ra) of the materials after being cured against a stainless steel surface was also measured with a portable, contact-type surface roughness tester (Mitutoyo Surftest SJ-201P). Five randomly picked sites with scans of $2.5 \mathrm{~mm}$ were done. Arithmetic means of profile deviations from the mean line $(\mathrm{Ra})$ were obtained from the instrument, which used the following formula to calculate Ra values:

$$
R a=\frac{1}{N} \sum_{i=1}^{N}|Y i|
$$

where $\mathrm{Ra}$ is roughness and $\mathrm{Yi}$ is profile deviation.

\section{Statistical analysis}

Statistical analysis was carried out on a personal computer using a statistical software (SPSS version 11.0 software, SPSS Inc., Chicago, IL, USA). The means and standard deviations of $\Delta \mathrm{E}^{*} \mathrm{ab}$ and $\mathrm{Ra}$ values were recorded for each material and analyzed with one-way ANOVA. Tukey's HSD test was applied to determine significant differences between groups.

\section{RESULTS}

Tables 2 and 3 show the total color difference $\left(\Delta \mathrm{E}^{*}\right.$ ab) values of soft denture liners after 96 hours of immersion in tea and coffee, respectively. The 

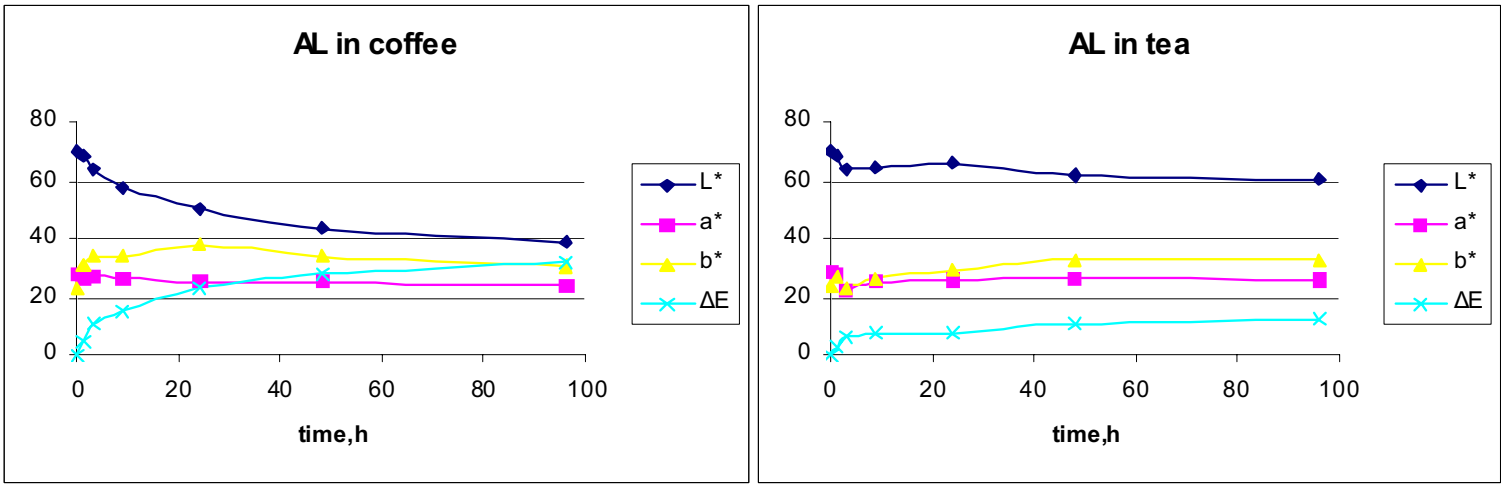

Fig. 1 Changes in $\mathrm{L}^{*}, \mathrm{a}^{*}, \mathrm{~b}^{*}$, and $\Delta \mathrm{E}$ ab as a function of time for $\mathrm{AL}$ in coffee and tea.
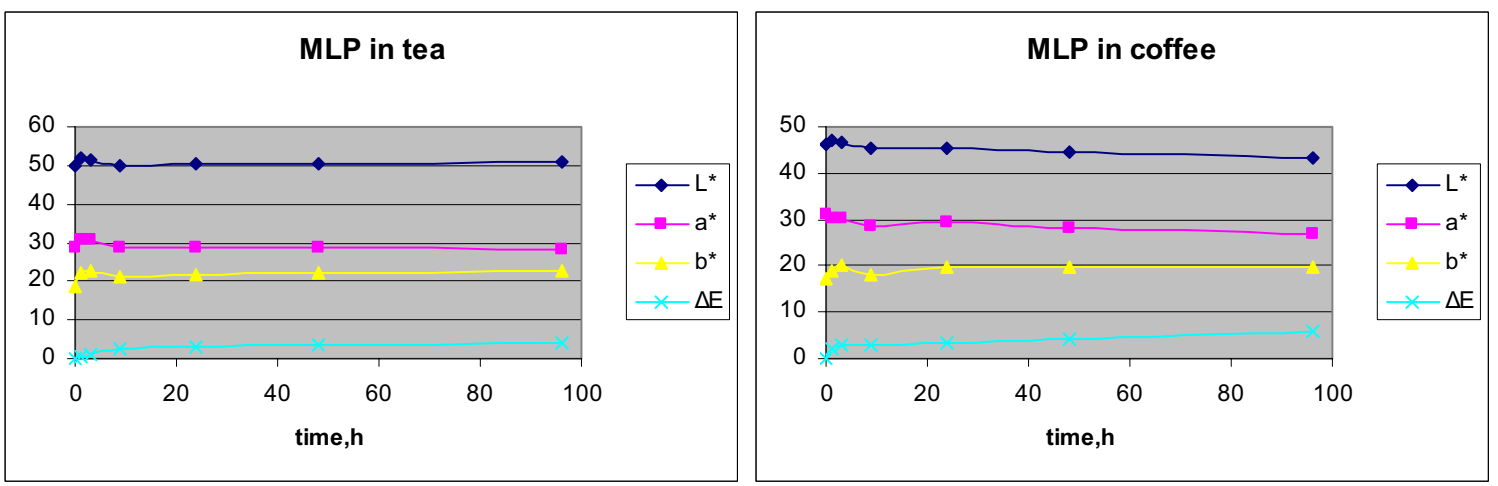

Fig. 2 Changes in $\mathrm{L}^{*}, \mathrm{a}^{*}, \mathrm{~b}^{*}$, and $\Delta \mathrm{E}$ ab as a function of time for MLP in coffee and tea.
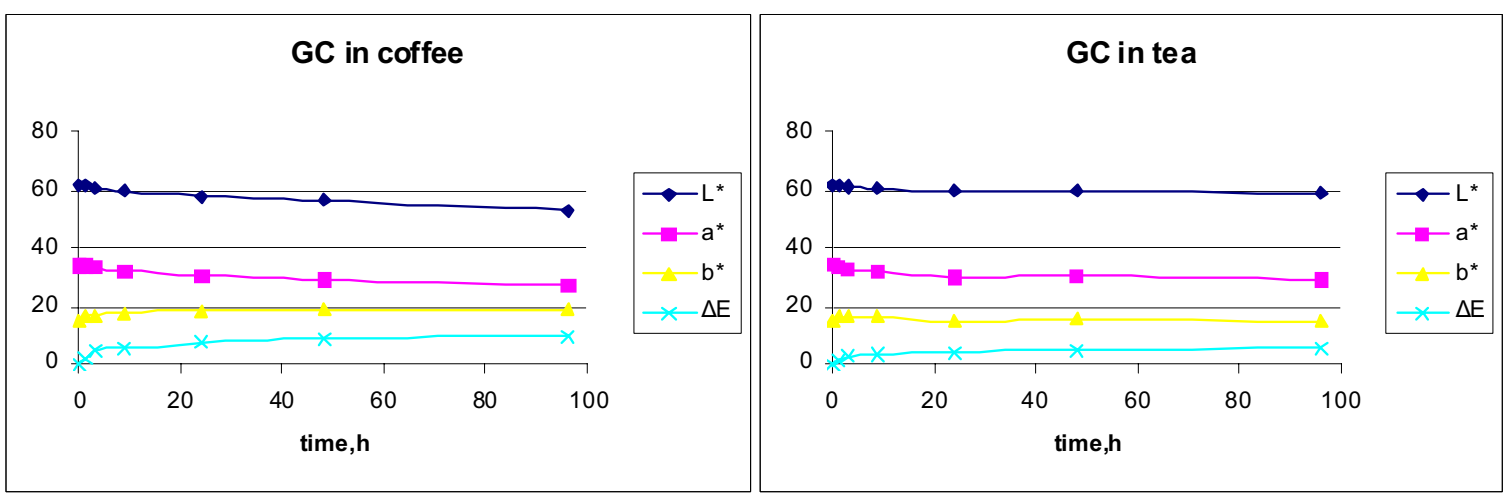

Fig. 3 Changes in $\mathrm{L}^{*}, \mathrm{a}^{*}, \mathrm{~b}^{*}$, and $\Delta \mathrm{E}$ ab as a function of time for $\mathrm{GC}$ in coffee and tea.
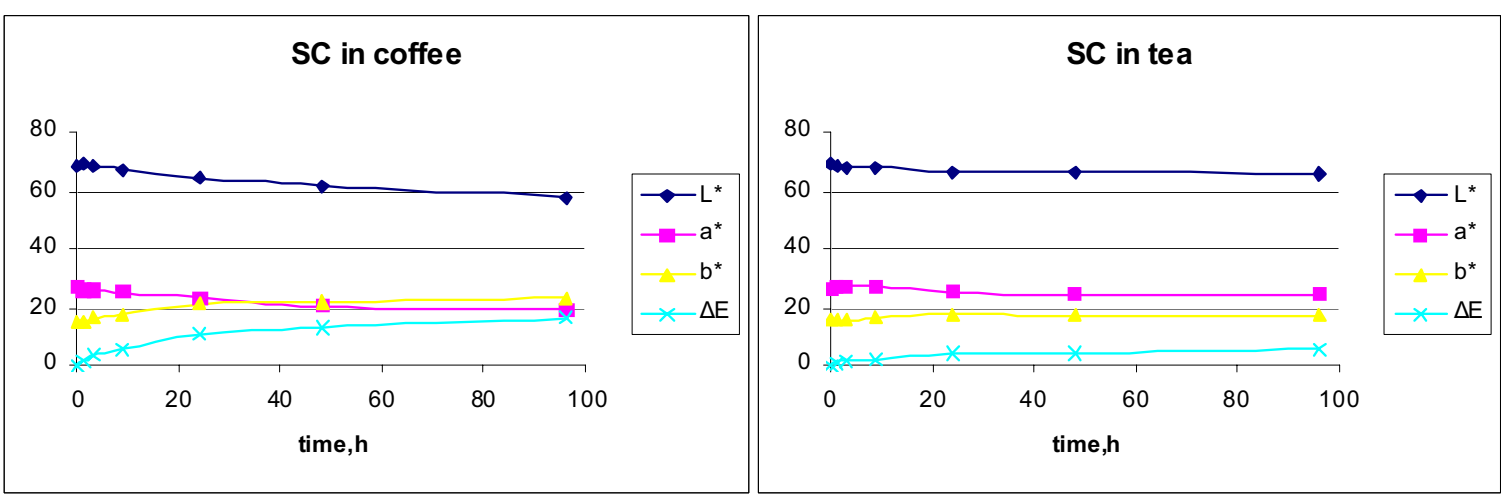

Fig. 4 Changes in $\mathrm{L}^{*}, \mathrm{a}^{*}, \mathrm{~b}^{*}$, and $\Delta \mathrm{E}^{*} \mathrm{ab}$ as a function of time for $\mathrm{SC}$ in coffee and tea. 

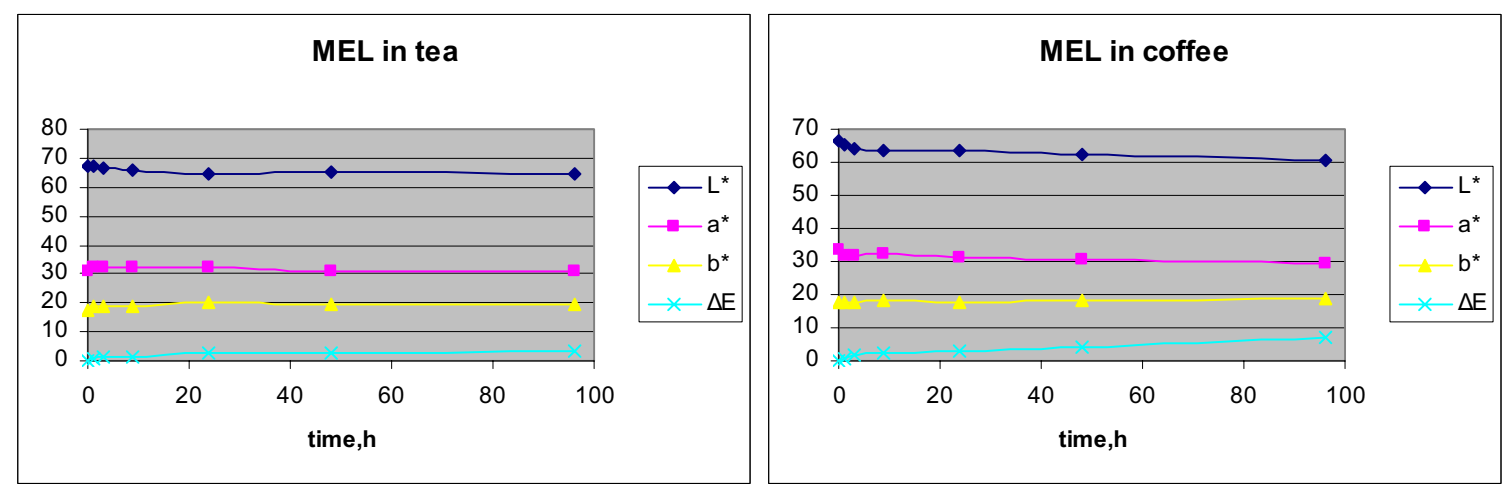

Fig. 5 Changes in $\mathrm{L}^{*}, \mathrm{a}^{*}, \mathrm{~b}^{*}$, and $\triangle \mathrm{E}^{*} \mathrm{ab}$ as a function of time for MEL in coffee and tea.

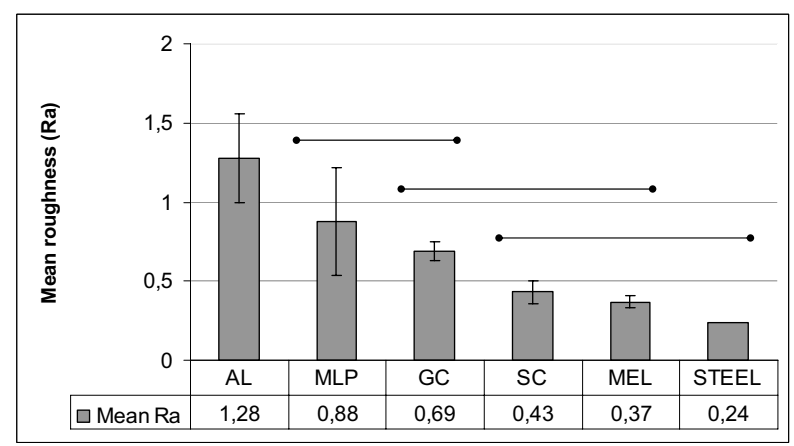

Fig. 6 Mean roughness $(\mathrm{Ra})$ values for the materials tested.

results showed that in both coffee and tea, MLP material showed better color stability than the other soft liner materials and was statistically similar to MEL denture base polymer which had the lowest value for both staining solutions. The AL material showed the poorest color stability after immersion in coffee and tea. After 96 hours' immersion in tea, there were no significant differences among MEL, MLP, SC, and GC ( $>>0.05)$. On the other hand, AL showed the highest discoloration and its $\Delta \mathrm{E}^{*} \mathrm{ab}$ value was significantly different from the other materials $(p<0.05)$ (Table 2). After the same immersion period in coffee, there were significant differences among the materials tested $(p<0.05)$ (Table 3). Hence, after 96 hours, coffee produced greater and statistically different $\Delta E^{*} a b$ values than tea for all the lining materials, except MLP.

Changes in $\mathrm{L}^{*}, \mathrm{a}^{*}, \mathrm{~b}^{*}$, and $\Delta \mathrm{E}^{*} \mathrm{ab}$ values as a function of time for each material are presented in Figs. 1-5. Among the materials tested, AL showed the most obvious change in $\mathrm{L}^{*}$ (i.e., light-dark character) with time, hence contributing to the largest increase in $\Delta \mathrm{E}^{*} \mathrm{ab}$ value. However, $\mathrm{a}^{*}$ and $\mathrm{b}^{*}$ values presented a much lower degree of change for AL. On the overall, for all the materials tested, a slight decrease in $a^{*}$ and a slight increase in $b^{*}$ were observed during the staining procedure.

Figure 6 shows the surface roughness measure- ment results, which revealed that the materials had different surface roughness values even if they were polymerized against the same steel surface. AL gave the highest $\mathrm{Ra}$ value (1.28), which was significantly higher than all the other surfaces tested $(p<0.05)$. MEL (0.37) and SC (0.43) gave statistically similar results compared to the steel standard (0.24) $(\mathrm{p}>0.05)$ (Fig. 6).

\section{DISCUSSION}

Color change is a useful indicator to dental operators of aging or damage of dental materials ${ }^{8}$. As such, color stability is a crucial prerequisite of dental materials as it determines their clinical serviceability. Color changes in dental materials may be assessed visually or by colorimetric analysis. Between these two methods, colorimetric evaluation is reported to be more precise than visual determination in measuring slight color differences on flat surfaces ${ }^{15)}$. On this basis, an instrumental colorimetric analysis was carried out in this study to eliminate subjective errors in color assessment.

Based on the data obtained through the colorimetric measurement procedure, the hypothesis tested in this study could be accepted. Indeed, slight differences among the materials in terms of material type, polymerization conditions, staining solution, and surface roughness resulted in different $\Delta E^{*} a b$ values. After 96 hours' immersion in the staining solutions, coffee produced greater color changes than tea in varying degrees for all the materials tested. However, this finding was not in agreement with a previous report by Büyükyllmaz and Ruyter ${ }^{13)}$ who demonstrated that the discoloration values of seven denture base materials were at the same level after 96 hours of immersion in coffee and tea solutions. Similarly, a study by Um and Ruyter ${ }^{12)}$ demonstrated that tea solution caused more discoloration than coffee after 48 hours of storage of five resin-based veneering materials in coffee and tea solutions. It was pointed out that the discoloration caused by tea 
was easily removed probably due to the adsorption of polar colorants from tea at the surface of these materials. With coffee, on the other hand, discoloration was probably due to both surface adsorption and absorption of colorants, and that the less polar colorants from coffee had penetrated deeper into the materials because the colorants were compatible with the polymer matrices of the composite resin materials. It should be noted that the surface properties of the materials used in this study were not comparable with resin-based veneering materials, thereby explaining the controversy between the results of those studies ${ }^{12,13)}$ and the present study. According to Lai et $a l .{ }^{14}$, the coffee solution stained the hydrophobic silicon materials more than the tea solution, and that hydrophobic materials were more prone to staining by hydrophobic solutions. The results obtained from the present study also supported this phenomenon, whereby significantly higher total color difference results were yielded when coffee solution was used.

$\Delta \mathrm{E}^{*} \mathrm{ab}$ value of MLP material exceeded 3.3 after 24 hours of immersion in coffee and tea, showing an unacceptable discoloration. As for AL material, its $\Delta \mathrm{E}^{*} \mathrm{ab}$ value exceeded 3.3 after one hour of immersion in coffee and three hours of immersion in tea. The only material group with acceptable discoloration value was observed to be MEL material in tea with a value of 3.07. Keskin ${ }^{11)}$ investigated the color stability of poly(methyl methacrylate) denture base polymers after immersion in coffee and tea solutions for seven days and reported that there was an initial increase, and then a decrease, in the discoloration values of the materials. This result was attributed to the removal of accumulated layers. As tea and coffee layers on specimens reached a certain thickness, they tended to break away from the surface of samples and return to the solution. This explanation would also account for the minor fluctuations observed for most of the materials in Figs. 1-5.

In the present study, it was found that MLP material showed the best color stability in both coffee and tea solutions among the soft denture liners. This result was consistent with that reported by Jin et $a l^{8)}$ who demonstrated that MLP had the best color stability among seven soft denture liners tested after being stored in denture cleansers for 180 days. This could be attributed to the high polymerization rate of heat-polymerized materials, and therefore a greater stability of physical properties. In the same vein, Anıl et al..$^{7}$ reported that there was a slight discoloration on MLP material after an accelerated aging procedure, while autopolymerized soft denture liners demonstrated the greatest color changes. Parallel to this finding ${ }^{7}$, the autopolymerized siliconbased soft denture liners - GC and SC - in this study showed more discoloration than heat-polymerized
MLP material after being stored in coffee solution for 96 hours. Despite having a smoother surface than MLP, the $\triangle \mathrm{E}^{*} \mathrm{ab}$ values of GC, SC, and MLP were $10.08,16.68$, and 8.22 respectively $(p<0.05)$.

Hulterström and Ruyter ${ }^{16)}$ stated that catalyst systems based on platinum compounds used in addition-type polymers were sensitive to small quantities of impurities, and thus more susceptible to color changes as in this study. Indeed, SC material which contained platinum compounds showed twice as much discoloration as MLP after being stored in coffee solution. On a separate note, in a color stability evaluation of five long-term soft denture liners in an accelerated aging chamber, Shotwell et al..$^{17)}$ reported that unpigmented soft denture liners demonstrated the least color change and that color changes seen with pigmented materials could be attributed to changes in the colorants used, a change in the color of elastomer, or both. They concluded that some colorants and elastomers might be affected by the high humidity or warmer temperature in the aging chamber. However, in an evaluation made by Jin et $a l^{8}{ }^{8}$, this effect was shown to be negligible because a $\Delta \mathrm{E}^{*} \mathrm{ab}$ value of less than 2 was obtained after 180 days of storage in distilled water and air.

All the silicon-based soft liners used in this study contained silica particles as filler in varying degrees. Aziz et al..$^{18)}$ stated that differences in the grade and concentration of the silica filler could be a factor influencing the hardness of silicon rubber maxillofacial prosthetic materials. They pointed out that a very high filler concentration increased polymer-filler interactions and thus reduced the mobility of polymer chains in dense and hard materials. Additionally, they claimed that the presence of surface-modified silica fillers in the polymer matrix had an effect on water absorption. While the presence of -OH groups on the surface of unmodified, hydrophilic silica fillers helps to absorb water into the polymer matrix, the surface groups on modified, hydrophobic silica fillers repel water molecules and hence prevent water absorption ${ }^{19}$. Although the types of silica fillers in the materials tested in the present study were not known, this explanation was useful in accounting for the differences in the roughness and color stability of the evaluated liners. This was chiefly because the main component of these liners was similar to that of silicon rubber maxillofacial materials - namely dimethylsiloxane polymer. Moreover, if the silica fillers contained in these liners were surface-modified and compatible with polysiloxane, then these materials could be said to be as color stable as MLP. However, with heat-polymerized materials, there is a temperature gradient from the surface of the material to the inside matrix. This might have caused constriction in the material, and thereby resulted in increased surface 
roughness.

AL material showed the poorest color stability after immersion in both solutions. This material was a light-cured soft liner which contained a poly(ethyl methacrylate) powder and a liquid part consisting mainly of butyl methacrylate and a plasticizer. High water sorption and solubility and a gradual hardening due to plasticizer leaching out are the main drawbacks of plasticized acrylics ${ }^{17)}$. Such behavior in water might have led to absorption and accumulation of the colorants. The presence of plasticizer in the composition of a liner increases chain stretching of small organic molecules in the polymer content, and this makes diffusion of staining solutions easier. Further, the staining agents may penetrate into the spaces created by the plasticizer leached out.

The samples prepared with AL soft liner material had a very rough surface when compared to the stainless steel surface it was cured against. Although surface roughness influences the surface adhesion of staining pigments ${ }^{20)}$ through mechanical interlocking, this parameter was not of primary importance in the absorption of coffee/tea pigments because these pigments penetrated into the liners. It seemed that the dominant attraction phenomenon between coffee/tea pigments and the soft liner material was that of physicochemical attraction. This phenomenon was similar to that in paint technology where the strength of interaction between pigment/ dye molecules and polymer resin is of primary importance in the retention of pigments in the resin. If this force is weak, the pigment leaches out easily. Another important aspect in paint technology is that good flexibility of both the backbone and side group improves the adhesion of polymer to the pigments. If the side groups have increased length, then there is also increased adhesion between the polymer and the pigments. The well-known fact is that poly(butyl methacrylate) (PBM) has a much longer side chain than PMMA, and therefore it displays stronger adhesion to the pigments. As such, in paint technology, PBM is the desired resin among all other acrylates. Based on these given reasons, the AL material in the current study exhibited higher absorption of coffee/ tea pigments than the other polymers tested. Besides, in agreement with the "like dissolve like" rule in organic chemistry, materials with silicon backbone showed lower absorption of organic pigments. This further accounted for the much higher tendency of $\mathrm{AL}$ material to absorb coffee/tea pigments than the other silicon-based polymers.

The data in Fig. 1 showed that the light-dark character presented the most obvious change, whereas the red-green and yellow-blue characters showed minimal changes throughout the staining procedure. A possible explanation for these data was that the change in color difference of $\mathrm{AL}$ was the result of dark-colored pigments accumulated on the surface rather than the change in red-green and yellow-blue characters of the inherent pigments. This was also in agreement with Jin et $a l^{8}{ }^{8}$, whereby it was stated that the inherent color probably showed minimal changes during a staining procedure. For all the materials tested, a slight decrease in $a^{*}$ and a slight increase in $b^{*}$ were observed as a general trend, with the colors of the samples changing toward green and yellow. This trend could be attributed to the contribution of the pigments from the staining solutions.

Results of this study provided useful insight to clinicians in the selection of soft denture lining materials. It seemed that the heat-polymerized soft denture liner was more color stable, and that silicontype soft denture liners were more resistant to staining than an acrylic-type soft denture liner.

\section{ACKNOWLEDGEMENTS}

Special thanks to Prof. Güngör Gündüz, Department of Chemical Engineering, Middle East Technical University, for his invaluable contributions in explaining the differences of the materials tested. In addition, we wish to express our thanks to Prof. Arife Doğan, Faculty of Dentistry, Gazi University, for her constructive advice in the preparation of this manuscript.

\section{REFERENCES}

1) Murata H, Taguchi N, Hamada T, Kawamura M, McCabe JF. Dynamic viscoelasticity of soft liners and masticatory function. J Dent Res 2002; 8:123-128.

2) Kawano F, Dootz ER, Koran A, Craig RG. Comparison of bond strength of six soft denture liners to denture base resin. J Prosthet Dent 1992; 68:368-371.

3) Sato Y, Abe Y, Okane H, Tsuga K. Finite element analysis of stress relaxation in soft denture liner. $\mathrm{J}$ Oral Rehabil 2000; 27:660-663.

4) Kawano F, Dootz ER, Koran A, Craig RG. Bond strength of six soft denture liners processed against polymerized and unpolymerized poly(methyl methacrylate). Int J Prosthodont 1997; 10:178-182.

5) Dootz ER, Koran A, Craig RG. Comparison of the physical properties of 11 soft denture liners. J Prosthet Dent 1992; 67:707-712.

6) Kawano F, Dootz ER, Koran A, Craig RG. Sorption and solubility of 12 soft denture liners. J Prosthet Dent 1994; 72:393-398.

7) Anıl N, Hekimoğlu C, Şahin S. Color stability of heatpolymerized and autopolymerized soft denture liners. J Prosthet Dent 1999; 81:481-484.

8) Jin C, Nikawa H, Makihira S, Hamada T, Furukawa $M$, Murata $H$. Changes in surface roughness and colour stability of soft denture lining materials caused by denture cleansers. J Oral Rehabil 2003; 30:125-130.

9) Hayakawa I, Keh ES, Morizawa M, Muraoka G, Hirano S. A new polyisoprene-based light-curing 
denture soft lining material. J Dent 2003; 31:269-274.

10) Canay Ş, Hersek N, Tulunoğlu I, Uzun G. Evaluation of colour and hardness changes of soft lining materials in food colorant solutions. J Oral Rehabil 1999; 26:821-829.

11) Keskin S. The treatment of prosthetic dental materials with hypochlorite. MSc Thesis (2002), Middle East Technical University, Ankara, Turkey.

12) Um CM, Ruyter IE. Staining of resin-based veneering materials with coffee and tea. Quintessence Int 1992; 22:377-386.

13) Büyükyılmaz Ş, Ruyter IE. Color stability of denture base polymers. Int J Prosthodont 1994; 7:372-382.

14) Lai YL, Lui HF, Lee SY. In vitro color stability, stain resistance, and water sorption of four removable gingival flange materials. J Prosthet Dent 2003; 90:293-300.

15) Bagheri R, Burrow MF, Tyas M. Influence of foodsimulating solutions and surface finish on suscepti- bility to staining of aesthetic restorative materials. $\mathrm{J}$ Dent 2005; 33:389-398.

16) Hulterström AK, Ruyter IE. Changes in appearance of silicone elastomers for maxillofacial prostheses as a result of aging. Int J Prosthodont 1999; 12:498-504.

17) Shotwell JL, Razzoog ME, Koran A. Color stability of long-term soft denture liners. J Prosthet Dent 1992; 68:836-838.

18) Aziz T, Waters M, Jagger R. Analysis of the properties of silicone rubber maxillofacial prosthetic materials. J Dent 2003; 31:67-74.

19) Waters MGJ, Jagger RG, Winter RW. Effect of surface modified fillers on the water absorption of a (RTV) silicone denture soft lining material. J Dent 1996; 24:297-300.

20) Zissis AJ, Polyzois GL, Yannikakis SA, Harrison A. Roughness of denture materials: A comparative study. Int J Prosthodont 2000; 13:136-140. 